\title{
Is abortion justified to save the life or health of a woman? Evidence of public opinion from Accra, Ghana
}

\author{
Sarah D. Rominski ${ }^{1, *}$ | April J. Bell ${ }^{2}$ | Alfred E. Yawson ${ }^{3}$ | Emmanuel K. Nakua ${ }^{4}$ | \\ Cheryl A. Moyer ${ }^{1}$
}

${ }^{1}$ Department of Obstetrics and Gynecology, University of Michigan, Ann Arbor, MI, USA

${ }^{2}$ Department of Epidemiology and

Biostatistics, Indiana University,

Bloomington, IN, USA

${ }^{3}$ Department of Community Health, College of Health Sciences, University of Ghana, Accra, Ghana

${ }^{4}$ Department of Epidemiology and Biostatistics, Kwame Nkrumah University of Science and Technology, Ashanti, Ghana

${ }^{*}$ Correspondence

Sarah D. Rominski, Department of

Obstetrics and Gynecology, University of

Michigan, Ann Arbor, USA.

Email: sarahrom@med.umich.edu

Funding Information

Institute for Research on Women and

Gender; University of Michigan

\begin{abstract}
Objective: In this study, we sought to determine to what extent the abortion law in Ghana is reflective of public opinion.

Methods: In a cross-sectional, community-based survey, individuals in two fishing communities in Accra were interviewed about their beliefs on abortion between May and July 2016, and sociodemographic, attitudinal, and experience data were collected. Factors associated with the outcome variable (abortion is justified to save the life/health of the woman: Yes/No) were entered into a multivariate logistic regression.

Results: A total of 508 participants completed the survey. Thirty-nine percent $(n=198)$ of the sample agreed that abortion was justified to save the life/health of the woman, with no significant differences in this finding when controlling for understanding of the law, gender, marital status, or personal experience of abortion in multivariate analysis. Higher education (odds ratio [OR] $1.64[P<0.001])$ and older age (OR $1.28[P<0.001])$ are positively associated with abortion being justified to save life/health, while those who have had an experience of unwanted sex are less likely to believe that (OR $0.60[P=0.029])$.
\end{abstract}

Conclusion: The participants held conservative views about the justification of abortion to save a woman's life and/or health. Improving access to safe abortion services will require acknowledgment of the broader social and cultural context that may make accessing such services difficult.

\section{KEYWORDS}

Abortion laws; Attitudes toward abortion; Ghana; Unsafe abortion

\section{1 | INTRODUCTION}

Abortion laws worldwide vary. In 49 countries, abortion is legally available on request, although usually restricted by gestational age. ${ }^{1}$ Nonetheless, approximately $40 \%$ of women of childbearing age (aged 15-49) live in countries with laws prohibiting abortion altogether or allowing the procedure only in order to save a woman's life, or to protect her physical or mental health. ${ }^{2}$ These more restrictive laws-most common in low- and middle-income countries-are often vestiges of colonialization, even though the former colonial powers have gone on to revise their own abortion laws. ${ }^{3}$

In the West African nation of Ghana, abortion is illegal, except if the pregnancy threatens the physical or mental health of the mother, if the pregnancy is the result of rape or incest, or in the case of fetal malformation. ${ }^{4}$ When juxtaposed against the outright prohibition of abortion under any circumstances in many other African nations, Ghana's law is considered comparatively liberal. ${ }^{5}$ Such a characterization was first underscored by the Ghana Health Service's Policies and 
Procedures Manual from 2006, and reinforced by the 2012 update, that instructs providers to interpret exceptions to the law broadly and provide women who need an abortion with safe, facility-based services. ${ }^{6,7}$ Despite such a context, abortion-related morbidity and mortality continue to be a problem in Ghana, suggesting that many women are seeking unsafe abortion services rather than seeking abortion from a trained provider.

Previous research suggests that many Ghanaians are unaware of the abortion laws in Ghana and are not clear on whether abortion is legal or illegal. ${ }^{8,9}$ In fact, in one assessment, Ghanaian women had the lowest correct level of general awareness and knowledge of abortion laws when compared across countries. ${ }^{8}$ In addition, while previous research has explored overall attitudes toward abortion in Ghana, ${ }^{10,11}$ little is known about perceptions regarding whether abortion is justified to save the life or health of the woman.

The aim of the present study was to assess the knowledge, attitudes, and beliefs of male and female community members in two fishing communities in Accra, Ghana, with regard to both the legality of abortion and its justification to save the life or health of the woman.

\section{2 | METHODS}

The study was conducted in two fishing communities in Accra (Chorkor in the Ablekuma South sub-metropolitan area and James Town in the Ashiedu Keteke sub-metropolitan area). These two fishing communities are urban areas in the south-eastern part of Accra, and are the most densely populated areas in the Greater Accra region, with large transitory population groups and large unemployed youth populations. These fishing communities are predominantly indigenous Ga-Adangmes.

A cross-sectional community-based survey was conducted between May 1 and July 31, 2016, in these two fishing communities. A semi-structured interview tool was developed to solicit information on knowledge, attitudes, and beliefs associated with abortion. In addition, the survey collected data on demographic characteristics, socioeconomic factors, sociocultural factors, gender, and high risk behaviors, and the circumstances under which respondents might believe abortion was justified, including to save the life or health of the woman. The survey was conducted in the language most preferred by the participant. Research assistants spoke English, Ga, and Akan (two of the local languages). The study team forward and back-translated the survey from English to both Ga and Akan, and research assistants had hard copies of the survey in all languages to guide them through. The study team held discussions to ensure words and phrases were clear in each language, and that participants would be able to answer each question. The data collection tool was pretested in Bukom, a neighborhood in the Ashiedu Keteke sub-metropolitan area of Accra with characteristics similar to the two communities taking part in the survey. Participants included resident men and women aged 15-49 years in the communities. Ethical clearance was obtained from the institutional review boards at the University of Ghana and the University of Michigan. A comprehensive verbal informed consent process was undertaken and documented for each participant.
The two fishing communities were divided in half geographically, resulting in four clusters. The modified WHO cluster sampling method was used to select 140 eligible individuals in each of the four clusters, for a total of 560 households. One adult member of each household was interviewed (the head of household or in his/her absence, a responsible adult member of the household was interviewed). Interviews were conducted with eligible and interested participants in a private room of the house. Often, women had babies with them during the interview, but no other people were present in the room with the surveyor and the participant. The team began surveying after morning chores were conducted (around 11:00 AM) and extended into the evenings, Monday through Saturday, in order to capture everyone in the homes, including those who worked outside the home during normal business hours.

Data were collected by trained research assistants using the Qualtrics offline data collection application for Android (Qualtrics, Provo, Utah, USA) on hand-held tablet computers. Data were uploaded nightly to a cloud-based server, where data were securely stored and accessible only to the research team.

Data were exported from Qualtricsto Microsoft Excel for cleaning and then into Stata V13.1 (StataCorp, College Station, TX, USA) for analysis. Data were cleaned, and frequencies and summary statistics were calculated. The dichotomous variable (abortion is justified to save the life or health of the woman) was used as the outcome variable in a series of bivariate logistic regression analyses. Those factors found to be significantly associated in bivariate analysis, as well as factors controlled for (including sex, personal [or partner] experience with abortion, and history of forced sex), were entered into a multivariate regression analysis. A $P$ value of 0.05 was considered statistically significant.

\section{3 | RESULTS}

A total of 544 participants completed the survey, 497 reported they had had sex and were then asked follow-up questions (had they ever used family planning, ever had sex when they did not want to), and 508 provided an answer to the outcome variable for the regression analyses. The majority of the sample $(306 / 544,56.3 \%)$ was female. More than half of the sample $(264 / 497,53.1 \%)$ had used a family planning method, and almost one-third (169/541, 31.2\%) had either had an abortion themselves (in the case of women) or had a partner who had had an abortion (in the case of men). More than a quarter of the sample $(140 / 497,28.2 \%)$ reported having sex when they did not want to $-34.2 \%$ of the women and $20.4 \%$ of the men answered the question, "Have you ever had sex when you did not want to?" in the affirmative.

Slightly less than $40 \%$ of respondents (198/508, 39.0\%) agreed that abortion was justified to save the life or the health of the woman (Table 1). This did not differ significantly between men and women $(P=0.112)$, nor between those who themselves or their partners had had a previous abortion and those who had not had a previous abortion $(P=0.148)$. While those who believed abortion was legal in Ghana 
TABLE 1 Sample characteristics and bivariate and multivariate regression analysis with abortion is justified to save the life and/or health of the woman as the outcome variable.

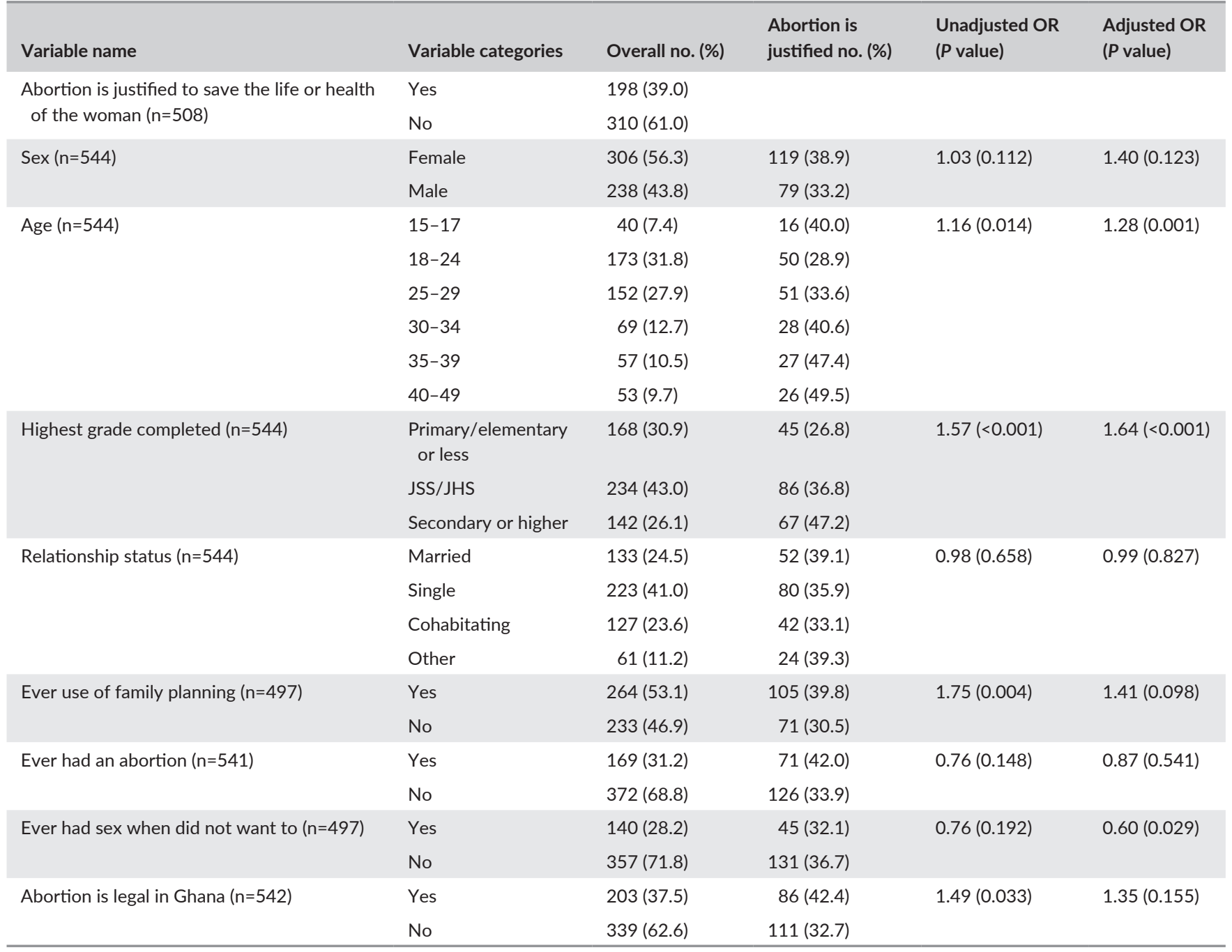

Abbreviations: JHS, junior high school; JSS, junior secondary school.

were significantly more likely to agree that abortion was justified to save the life and/or health of the woman than those who believed abortion was illegal in bivariate analysis $(P=0.033)$, this did not remain significantly associated in multivariate analysis. Similarly, while having used family planning was significantly associated with the outcome variable in bivariate assessment, this association was lost in the multivariate model.

In multivariate regression analysis, the factors significantly positively associated with believing abortion was justified to save the life and/or health of the woman were age (OR 1.28, $P<0.001)$, and being more highly educated (OR 1.64, $P<0.001$ ), and significantly negatively associated with having an experience of forced sex (OR 0.60, $P=0.029$ ).

\section{4 | DISCUSSION}

In the present community-based survey in Accra, Ghana, nearly twothirds of participants did not believe abortion was justified to save the life and/or health of the woman, one of the provisions in Ghanaian law under which abortion is legally permissible. This belief did not significantly vary by whether participants or their partners had had an abortion themselves-meaning that individuals who had had an abortion were just as likely as those who hadn't to say that abortion was not justified to save the life and/or health of the woman. Older respondents and those with higher levels of education were the most likely to state that abortion was justified to save the life and/or health of the woman.

Our findings reflect one of very few studies investigating the views of the general public toward abortion in Ghana or sub-Saharan Africa. Participants in those studies that have been conducted show generally conservative views toward abortion, ${ }^{12,13}$ similar to the findings of the present study. Surprisingly, in the current study, belief in the justification of abortion was not related to an individual's experience accessing an abortion, was negatively associated with having an experience of unwanted sex, and was not associated with the belief that abortion is legal in the country. We found that women and men hold similarly 
conservative views toward the justification of abortion, which differs from the findings of previous work. ${ }^{14-16}$ In Burkina Faso, another West African nation, Rossier ${ }^{14}$ found that women were markedly more tolerant of abortion than were men. In Cameroon, while women did not condone abortion, it was seen as the "lesser shame"; a mistimed pregnancy was more socially objectionable than was having an abortion. ${ }^{17}$ In Kenya, Izugbara and colleagues ${ }^{18,19}$ found that, while the women in their study did not advocate for or defend abortion, they also did not condemn it, and saw it as a way to manage socially unacceptable pregnancies. The men in the study, however, denounced abortion. Izugbara et al. suggest this is because women having abortions are using their reproductive capacity and sexuality autonomously, challenging male control of women's bodies and sexuality. In our study, we did not delve into the reasons why individuals held the views they did, and so cannot compare our findings to those of other settings where views contrary to abortion were due to female autonomy or sexuality. We found increasing age and education level were associated with holding a more liberal view toward the justification of abortion to save the life of the woman. The relationship between increasing education and more acceptance of abortion was also noted in Burkina Faso. ${ }^{14}$

In many settings, including Ghana, conservative views toward the justification of abortion may be an important barrier to women seeking safe abortion services, although this barrier receives less attention than other health system barriers, such as provider shortages. WHO, for example, has published guides for health systems and providers, ${ }^{20,21}$ but work to change the attitudes of the general population or policymakers is scarce. ${ }^{22}$ Investigating, conceptualizing, and addressing abortion-related stigma at all levels is a newer field of research. This includes individual woman's internalization of stigma, as well as the stigma instigators. ${ }^{23,24}$

While providing comprehensive sexual education is controversial, especially in socially conservative areas, this could be an important way to improve the knowledge of safe abortion services and to reduce the morbidity and mortality associated with unsafe abortion. While changing community views around areas where there is stigma is challenging, there are lessons that can be drawn from areas with high prevalence of HIV where cross-sectorial mass communication interventions have been successful at reducing the stigma of highly personal and sensitive issues. Of course, HIV and abortion differ in important ways, such as the chronic nature of HIV as compared to the episodic nature of abortion. ${ }^{22}$ Many successful HIV stigma-reducing initiatives have involved people living with HIV as integral members of the teams. Women who have an abortion may not want to be involved in such interventions and may want to simply move on from their abortion experience. However, including abortion as part of routine, comprehensive sexual and reproductive healthcare in an effort to remove its stigmatization is an important step to reducing unsafe abortion and the morbidity and mortality that can follow.

The present cross-sectional study of the attitudes of citizens of Accra, Ghana regarding abortion had some important limitations that should be noted. Given the cross-sectional nature of the data, it was impossible to assign causality to any of the associations reported. Second, given some of the seemingly contradictory findings of the investigation, such as participants who had experienced sex when they did not want it showing less support for abortion to save the health and/or life of the woman, more in-depth qualitative assessment of these phenomena is warranted. Finally, given the limited sample size and geographical distribution of these participants, our ability to generalize the findings would also be limited. Despite these limitations, we believe the investigation has begun to look at a social phenomenon that is largely unstudied, and which warrants further study.

Attitudes toward abortion in urban Ghana suggest that women face significant social and cultural hurdles to seeking safe abortion services, regardless of the availability of services. As others have suggested, ${ }^{25}$ while changes in legal restrictions undoubtedly reduce macro-level barriers to safe abortion care, cultural and religious constraints at both the individual and community levels can persist.

\section{AUTHOR CONTRIBUTIONS}

AJB, CAM, and AY conceived and designed the study. AJB and AY oversaw data collection. SDR led the data analysis and wrote the first draft of the manuscript. All authors contributed to the interpretation of the data and revised the manuscript.

\section{ACKNOWLEDGMENTS}

This study was funded in part by a faculty seed grant from the Institute for Research on Women and Gender, University of Michigan.

\section{CONFLICTS OF INTEREST}

The authors have no conflicts of interest.

\section{REFERENCES}

1. Finer L, Fine JB. Abortion law around the world: Progress and pushback. Am J Public Health. 2013;103:585-589.

2. Singh S, Wulf D, Hussain R, Bankole A, Sedgh G. Abortion Worldwide: A Decade of Uneven Progress. New York: Guttmacher Institute; 2009.

3. Culwell KR, Hurwitz M. Addressing barriers to safe abortion. Int J Gynecol Obstet. 2013;121:S16-S19.

4. Morhe RAS, Morhe ESK. Overview of the law and availability of abortion services in Ghana. Ghana Med J. 2006;40:80-86.

5. Sundaram A, Juarez F, Bankole A, Singh S. Factors associated with abortion-seeking and obtaining a safe abortion in Ghana. Stud Fam Plann. 2012;43:273-286.

6. Ghana Health Service (GHS). Prevention and Management of Unsafe Abortion: Comprehensive Abortion Care Services Standards and Protocols. 2006.

7. Ghana Health Service (GHS). Prevention and Management of Unsafe Abortion: Comprehensive Abortion Care Services Standards and Protocols. 2012

8. Assifi AR, Berger B, Tunçalp Ö, Khosla R, Ganatra B. Women's awareness and knowledge of abortion laws: A systematic review. PLoS ONE. 2016;24(11):e0152224.

9. Ghana Statistical Service (GSS), Ghana Health Service (GHS), and ICF. Ghana Maternal Health Survey 2017. Accra, Ghana: GSS, GHS, and ICF; 2018. 
10. Morhe ES, Morhe RA, Danso KA. Attitudes of doctors towards establishing safe abortion units in Ghana. Int J Gynecol Obstet. 2007;98:70-74.

11. Konney TO, Danso KA, Odoi AT, Opare-Addo HS, Morhe ESK. Attitude of women with abortion-related complications toward provision of safe abortion services in Ghana. J Womens Health. 2009;18:1863-1866.

12. Geary CW, Gebreselassie H, Awah P, Pearson E. Attitudes towards abortion in Zambia. Int J Gynecol Obstet. 2012;118(Suppl S):S148-S151.

13. Rominski SD, Darteh E, Dickson K, Munro-Kramer M. Attitudes towards abortion among students at the University of Cape Coast, Ghana. Sex Reprod Healthc. 2017;11:53-59.

14. Rossier C. Abortion: An open secret? Abortion and social network involvement in Burkina Faso. Reprod Health Matters. 2007;1(15):230-238.

15. Craig B, O'Brien D. Abortion and American Politics. Chatham, NJ: Chatham House Publishers; 1993.

16. Ladd EC, Bowman K. Public Opinion About Abortion. Washington, DC: The AEI Press; 1997.

17. Johnson-Hanks J. The lesser shame: Abortion among educated women in Southern Cameroon. Soc Sci Med. 2002;55:1337-1349.
18. Izugbara CO, Egesa C, Okelo R. 'High profile health facilities can add to your trouble': Women, stigma and un/safe abortion in Kenya. Soc Sci Med. 2015;141:9-18.

19. Izugbara CO, Otsola KJ, Ezeh AC. Men, women, and abortion in Central Kenya: A study of lay narratives. Med Anthropol. 2009;28:4.

20. World Health Organization. Health Worker Roles in Providing Safe Abortion Care and Post-Abortion Contraception. Geneva: World Health Organization; 2015.

21. World Health Organization. Safe Abortion: Technical and Policy Guidance for Health Systems, 2nd edn. Geneva: World Health Organization; 2012.

22. Culwell KR, Hurwitz M. Addressing barriers to safe abortion. Int J Gynecol Obstet. 2013;121(S1):S16-S19.

23. Kumar A, Hessini L, Mitchell EM. Conceptualising abortion stigma. Cult Health Sex. 2009;11:625-639.

24. Kimport K, Cockrill K, Weitz TA. Analyzing the impacts of abortion clinic structures and processes: A qualitative analysis of women's negative experience of abortion clinics. Contraception. 2012;85:204-210.

25. Trueman KA, Magwentshu M. Abortion in a progressive legal environment: The need for vigilance in protecting and promoting access to safe abortion services in South Africa. Am J Public Health. 2013;103:397-399. 